\title{
Isolation and characterization of phage AHP-1 and its combined effect with chloramphenicol to control Aeromonas hydrophila
}

\author{
H. P. S. U. Chandrarathna ${ }^{1} \cdot$ Chamilani Nikapitiya $^{1}$ - S. H. S. Dananjaya ${ }^{1} \cdot$ B. C. J. De Silva ${ }^{2} \cdot$ Gang-Joon Heo $^{2} \cdot$ \\ Mahanama De Zoysa ${ }^{1}$ (D) $\cdot$ Jehee Lee ${ }^{3,4}$
}

Received: 29 April 2019 / Accepted: 14 October 2019/Published online: 5 November 2019

(C) Sociedade Brasileira de Microbiologia 2019

\begin{abstract}
To develop an alternative bio-control measure for multi-drug resistant pathogenic Aeromonas hydrophila, which causes motile Aeromonas septicemia in fish, novel virulent phage (AHP-1) was isolated from carp tissues. Morphological analysis by transmission electron microscopy revealed that AHP-1 belongs to Myoviridae family. AHP-1 displayed $81 \%$ of moderate adsorption by $25 \mathrm{~min}$, and latent period of $40 \mathrm{~min}$ with burst size of $97 \mathrm{PFU} \mathrm{mL}^{-1}$ at an optimal multiplicity of infection (MOI) 0.1. AHP-1 was stable over a broad range of $\mathrm{pH}(4-11)$, temperature $\left(4-50^{\circ} \mathrm{C}\right)$, and salinity $(0.1-3.5 \%)$. Both time and MOI dependent in vitro A. hydrophila growth inhibition was observed with AHP-1. AHP-1 (10 MOI) showed higher growth inhibition against A. hydrophila than chloramphenicol $\left(5 \mu \mathrm{g} \mathrm{mL}^{-1}\right)$, and combined treatment was more promising than individuals. Immune gene expression analysis of zebrafish upon continuous bath exposure to AHP-1 resulted significantly higher (il-6 and sod-1) or slight induction (tnf- $\alpha, i l 1-\beta, i l-10$, and $c x c l-8 a$ ) than controls at beginning of the phage exposure, but those lowered to basal level by day 12 post-phage exposure. It suggests no adverse immune responses have occurred for the AHP-1 dose that used, and have potential for the phage therapy. Further detailed in vivo studies are needed to confirm the protective efficacy of newly isolated AHP-1 against A. hydrophila infection.
\end{abstract}

Keywords A. hydrophila $\cdot$ Chloramphenicol $\cdot$ Fish pathogen $\cdot$ Immune responses $\cdot$ Phage AHP-1 $\cdot$ Multi-drug resistance

Responsible Editor: Fernando R. Spilki

Electronic supplementary material The online version of this article (https://doi.org/10.1007/s42770-019-00178-z) contains supplementary material, which is available to authorized users.

Mahanama De Zoysa

mahanama@cnu.ac.kr

Jehee Lee

jehee@jejunu.ac.kr

1 College of Veterinary Medicine, Chungnam National University, Yuseong-gu Daejeon 34134, Republic of Korea

2 Veterinary Medical Center and College of Veterinary Medicine, Chungbuk National University, Cheongju 28644, Republic of Korea

3 Fish Vaccine Research Center, Jeju National University, Jeju-si, 63243 Jeju, Self-Governing Province, Republic of Korea

4 Department of Marine Life Sciences, Jeju National University, Jeju-si, 63243 Jeju, Self-Governing Province, Republic of Korea

\section{Introduction}

Since the first antibiotic, penicillin being discovered in early 1900 s, antibiotics played a major role in medicine as a highly effective treatment for many infectious diseases $[1,2]$. Unfortunately, the era of antibiotics seems to be ending as the cases of anti-microbial resistance (AMR) are increasing at an alarming rate globally, and the emergence of multidrug-resistant (MDR) highly virulent bacterial pathogens has been accelerated in past few decades posing a serious threat on public health. For example, it has been reported that 99,000 deaths occur annually by antibiotic-resistant pathogenassociated hospital-acquired infections (HAIs) such as pneumonia and sepsis in the USA [2]. Overuse and inappropriate use of antibiotics have been the principal causes of resistance evolution. Aquaculture, which is the fastest growing section of food industry, is not an exception in extensive antibiotic usage to control diseases as well as a growth supplement. According to a recent study, approximately $0.53 \mathrm{~kg}$ of antibiotics had been utilized per a ton of harvested salmon in Chilean salmonid farms, in 2016 [3]. 
Bacteriophages (phages), the most abundant biological entities on earth, are viruses specifically infecting their bacterial hosts. Phages either cause bacteria lysis or multiply within the bacteria as temperate phages. Phages have been discovered more than a century ago. Since then, they were isolated, characterized, and phage-related bio-engineering techniques such as phage display and recombinant phages were developed to enhance their therapeutic potential [4]. At present, phages are gathering fame as an alternative therapeutic agent to antibiotics due to the rise of MDR bacteria. For instance, some countries are undertaking a phase/II clinical trials on safety and efficacy of phage therapy [5].

Generally, the bacteriophage families are classified according to virion morphology and type of nucleic acid, and more than 40 criteria are considered for genera and species differentiation. Among tailed bacteriophages, order Caudovirales, family Myoviridae accounted about 24\% (as of 2001) of reported bacteriophages [6]. Family Myoviridae is morphologically characterized with an icosahedral head separated by the neck, and a long contractile tail composed of inner hollow tube and sheath. They are the most highly evolved and abundant tail phages, and enterobacteria phage T4 is a typical example of myophage [6]. More than 40 Aeromonas phages have been morphologically characterized as tailed phages, and the highest were found to be under family Myoviridae in the natural environments $[6,7]$.

Aeromonas hydrophila, a Gram-negative, rod-shaped and facultative anaerobic bacterium, is ubiquitous in both freshwater and marine aquatic environments. It is notorious as an opportunistic pathogen in humans and animals, especially in aquatic organisms, causing heavy economic losses in globel aquaculture. In humans, A. hydrophila is responsible for bacteraemia, acute diarrhea, and skin and soft tissue infections, while it is the main causative agent of Aeromonas septicaemia and ulcerative infections in wild and farmed fish $[8,9]$. The most widely used approach for controlling Aeromonas infections is still recognized as antibiotic therapy; however, recent studies have reported isolation of MDR A. hydrophila from diseased fish and aquatic systems worldwide $[10,11]$. Isolation and characterization of phages virulent to pathogenic A. hydrophila are therefore important to develop as an alternative theraputics to the use of antibiotics.

The goal of this study was to develop an efficient biocontrol method, which can be used as an alternative treatment for fish pathogenic A. hydrophila. For this purpose, we isolated and characterized, a virulent phage (AHP-1) which infects and inhibits the growth of previously isolated pathogenic strain of MDR A. hydrophila [10]. Furthermore, in vitro bacterial growth inhibition by AHP-1 was compared with commonly used antibiotic, chloramphenicol, and their combination. To understand the safety of the mode of phage administration, in vivo immune gene responses of zebrafish were analyzed during 12 days of continuous bath exposure to AHP-1.

\section{Materials and methods}

\section{Isolation and characterization of AHP-1}

Mixture of fish tissues (digestive tract, kidney, liver, spleen, skin) of Crucian carp, Carassius carassius (bought from a local fish market) were dissected and enriched with previously isolated A. hydrophila strain [10] using a standard enrichment technique. The phage characterization procedures were same as stated in Nikapitiya et al. [12] and, only modified or specific methods were described in the relevant sections. The plaques were separately picked, eluted to the SM buffer ( $\mathrm{pH} 7.5)(50 \mathrm{mM}$ Tris $\mathrm{HCl} ; \mathrm{pH} 7.4,0.1 \mathrm{mM} \mathrm{NaCl}, 8 \mathrm{mM} \mathrm{MgSO} 4$ ), and purified through three consecutive elutions. The concentrated phage lysate was further purified by polyethanol glycol and sodium chloride precipitation, followed by dialysis. AHP-1 titer was determined by standard soft agar overlay method, and recorded as PFU $\mathrm{mL}^{-1}$. Purified phage was stored in SM buffer ( $\mathrm{pH} 7.5)$ at $4{ }^{\circ} \mathrm{C}$. To characterize the phage morphology, transmission electron microscopy (TEM) image (Bio-TEM; Hitachi, Japan) of AHP-1 was taken after negatively strained with $2 \%$ uranyl acetate. Pre-exponential cultures of $A$ hydrophila were used to determine latent period, rising period and the burst size, by one step growth profile, and adsorption rate and adsorption rate constant $(K)$ of AHP-1 by adsorption curve, at 0.1 MOI. Thirty-six bacterial strains belong to various genera: A. hydrophila (06), A. salmonicida (04), A. sobria (01), A. bivalvia (01), A. caviae (01), A. veronii (02), Morganella sp. (02), Edwardsiella tarda (03), Enterobacter sp. (01), Enterococcus faecium (01), Escherichia coli (01), Klebsiella pneumoniae (02), Streptococcus iniae (02), S. parauberis (03), Vibrio $s p$. (05), and Lactococcus sp. (01) were used to determine the host range of AHP-1 by spot assay.

\section{Survival and stability of AHP-1}

Stability assays in a range of temperatures $\left(4-65^{\circ} \mathrm{C}\right), \mathrm{pH}(2-$ $14)$, salinity $(0.1-3.5 \%)$, and in different organic solvents (PBS, diethyl ether, chloroform, acetone, and ethanol) were performed to investigate the survivability or the sensitivity of the AHP-1. Briefly, $100 \mu \mathrm{L}$ of phage was inoculated to 900 $\mu \mathrm{L}$ SM buffer and incubated in abovementioned conditions or solvents for $1 \mathrm{~h}$, and then surviving phages were quantified by soft agar assay. To determine the $\mathrm{pH}$ and salinity stability, $\mathrm{pH}$ or salinity adjusted SM buffer was used. For the solvent stability, SM buffer was substituted by the particular solvent. The data were analyzed by one-way of analysis of variance and unpaired $t$ test for statistically significance $(P<.05)$ using GraphPad Prism 6.0. (USA). 


\section{A. hydrophila growth inhibition by AHP-1}

Inhibition of A. hydrophila growth was tested using a series of MOIs of AHP-1 (10-0.01) as described by Nikapitiya et al. [12]. Moreover, individual growth inhibition effect of A. hydrophila was determined by turbidimetric method using different concentrations $\left(2.5-25 \mu \mathrm{g} \mathrm{mL}^{-1}\right)$ of chloramphenicol. Briefly, pre-exponential cultures of A. hydrophila were treated with the respective doses of chloramphenicol, incubated in $180 \mathrm{rpm}$ shaker at $25^{\circ} \mathrm{C}$, and recorded the $\mathrm{OD}_{595}$ until $24 \mathrm{~h}$. Among those values, dose that showed more than $\mathrm{OD}_{595}$ $=0.5$ within $24 \mathrm{~h}$ was considered for further experiments. After selecting the individual AHP-1 and chloramphenicol doses, the AHP-1 and chloramphenicol combined growth inhibition effect was determined using 10 MOI AHP-1 with $5 \mu \mathrm{g} \mathrm{mL} \mathrm{m}^{-1}$ chloramphenicol by turbidimetric method until $24 \mathrm{~h}$, and $\mathrm{OD}_{595}$ was recorded until $24 \mathrm{~h}$.

\section{Immune gene expression analysis of AHP-1 in adult zebrafish}

AHP-1 was administered to wild-type AB zebrafish (mean weight $0.55 \pm 5 \mathrm{~g}, n=36$, in duplicates) as bath exposure $\left(9.85 \times 10^{5} \mathrm{PFU} \mathrm{mL} \mathrm{m}^{-1}\right)$, continuously for 12 days, while the control group was exposed to the same volume of SM buffer. Constant phage titer levels were maintained in the tanks by renewing water, and adding fresh AHP-1 daily. Tissue sampling $(n=3)$ was done at days 1,4 , and 12 post-exposure. Kidney tissue was surgically removed, snap-frozen in liquid nitrogen, and stored in $-80{ }^{\circ} \mathrm{C}$. RNA isolation, cDNA synthesis, and quantitative real time (qRT)-PCR were performed (primer list; Table S1) to detect relative mRNA expression levels of $\operatorname{sod}-1, \operatorname{tinf}-\alpha$, $i l 1-\beta$, il-6 and $i l-10$, and $c x c l-8 a$ were as explained previously [10]. Control vs AHP-1 exposed expression data were analyzed for statistical significance $(P<.05)$ by unpaired $t$ test (GraphPad Prism 6.0., USA).

\section{Results and discussion}

\section{Isolation and characterization of AHP-1}

A. hydrophila isolates from diseased fish or aquaculture farms worldwide have shown multi-drug resistance to a number of commonly used antibiotics, and some are found to be associated with mass mortalities of cultured fish [13-15]. Therefore, development of alternative therapeutics which are able to substitute currently used antibiotics, has been a timely need. In the present study, as an alternative to control MDR bacterial infection, phage AHP-1 was isolated and characterized. Plaque diameter of AHP-1 was measured as $<1 \mathrm{~mm}$ and has clear centers surrounded by thin halozone (Fig. 1a). TEM images indicated that AHP-1 consisted with icosahedral head of approximately $129.4 \mathrm{~nm}$ in diameter and contractile tail $\times$ base width was $\sim 124.3 \times 33.2 \mathrm{~nm}$ (Fig. 1b). Thus, AHP-1 showed high probability of belonging to family Myoviridae. Many phages virulent to genus Aeromonas are also found to be categorized under family Myoviridae such as $\Phi 2, \Phi 5$ [16], and BPA6 [17] infecting A. hydrophila, and ASP-1[12], SW69-9, L9-6, and Riv-10 [18] infecting A. salmonicida subsp. salmonicida.

Even though the reduction was less than $1 \log$, comparatively rapid adsorption was occurred in first $4 \mathrm{~min}$, followed by slower adsorption phase thereafter (Fig. 1c). At the end of $25 \mathrm{~min}$, phage adsorption reached $81.5 \%$ of total phage with $3.06 \times 10^{-8} \mathrm{~mL} \mathrm{m^{-1 }}$ of adsorption rate constant $(K)$. As described in Le et al. [7], A. hydrophila phage adsorption reached over $90 \%$ during $40 \mathrm{~min}$, while in ElAraby et al. [18] it showed $51 \%$ and $66.8 \%$ of adsorption after 20 and $30 \mathrm{~min}$, respectively. AHP-1 displayed 40min long latent period, $20 \mathrm{~min}$ of rising period, and burst size of 97 plaque forming units (PFU) per infected cells (Fig. 1d). Latent periods and burst sizes of reported Aeromonas phages differed over a wide range, considerably high burst size (626 PFU/infected cells) and short latent period (15 min) [19] to very low burst size (2 PFU/infected cells) and long latent periods $(150 \mathrm{~min})$ [17]. These two parameters in our study were compatible with reported A. hydrophila phages [18], and showed smaller burst size compared to BPA6 [16] and $\Phi 2$ [7]. However, burst size or latent period significantly varied among the studied phages; mean survival rate of infected animals after phage treatments did not correlate significantly with those traits [20].

AHP-1 found infectious to two other A. hydrophila lab strains and previously isolated A. salmonisida subsp. salmonisida strain [10] by exhibiting clear zones on bacterial lawns (data not shown). None of the other bacterial strains belong to other genera were susceptible to AHP-1. Specificity of phage infection is mainly associated with nature and structural variances, localization, and number and density of specific receptors on bacteria cell surface [21]. Previously isolated $A$. hydrophila phages were either showed narrow host ranges only infecting to their indicator host [18] or broad host ranges [7, 22] over many clinical and environmental isolates of Aeromonas species. With the feature of narrow host range, AHP-1 can be used as a candidate for preparing phage cocktails against Aeromonas infections in aquaculture systems; however, screening more Aeromonas species for host range would be more advantageous to expand the therapeutic potential of isolated AHP-1.

\section{Survival and stability of AHP-1}

Knowledge on the phage stability is important when phages are subjected to industrial processes such as manufacturing 

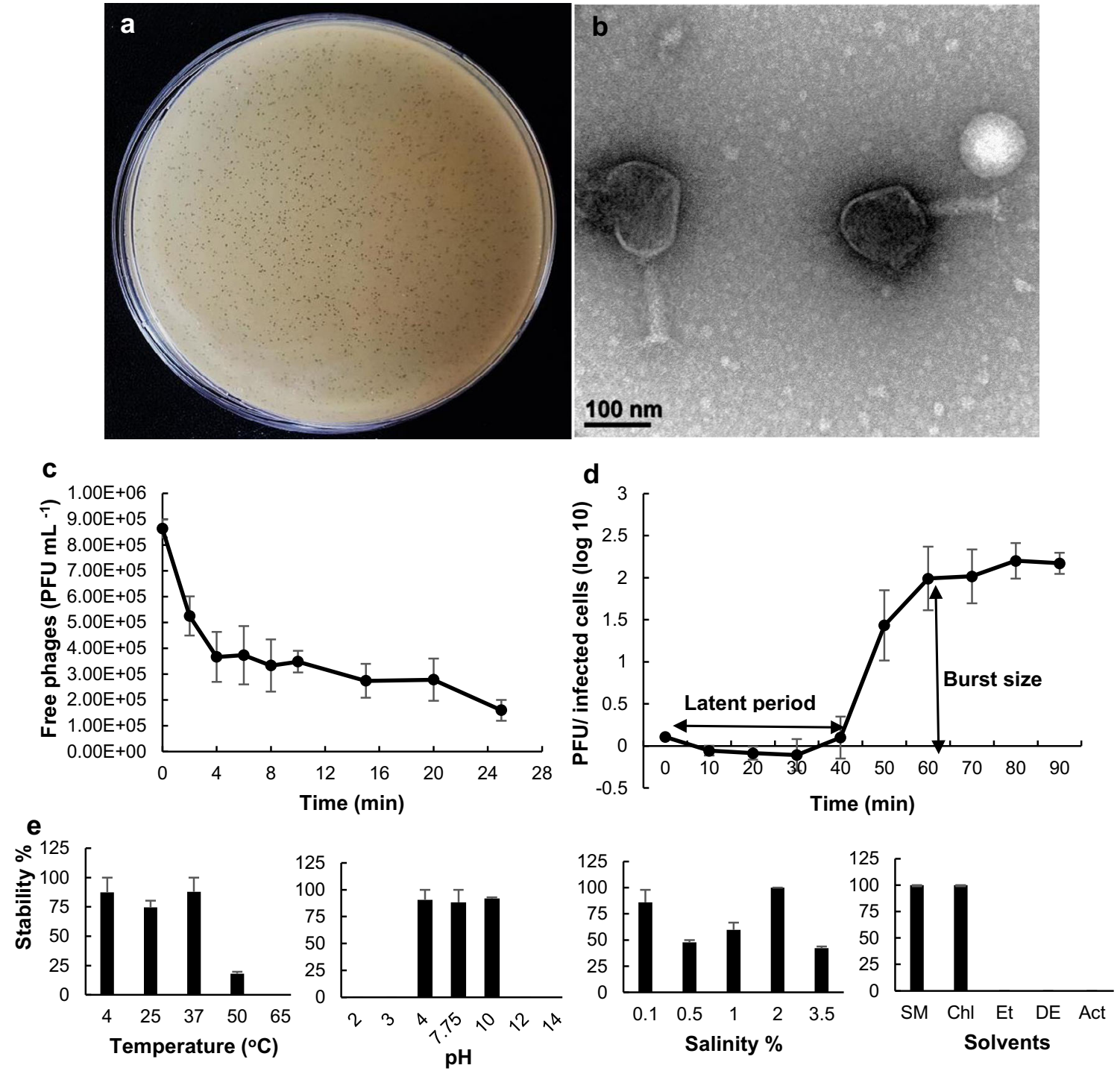

Fig. 1 Characterization of AHP-1: a plaque morphology, b TEM image showing icosahedral head and sheathed tail tube with tail fiber of AHP-1. Bar $=100 \mathrm{~nm}, \mathbf{c}$ adsorption curve, $\mathbf{d}$ one-step growth profile of AHP-1 indicating burst size and latent period. All the experiments were conducted at $\mathrm{MOI}=0.1$ as independent duplicate experiments, e stability of AHP-

medicated feed, where high temperatures and different $\mathrm{pH}$ or solvents are often used. Stability tests confirmed that AHP-1 can survive under a wide range of temperatures $\left(4-50^{\circ} \mathrm{C}\right)$, even though the infectivity decreased by $75 \%$ at $50{ }^{\circ} \mathrm{C}$ (Fig. 1e). No significant viability $(P>.05)$ differences of phage between $4{ }^{\circ} \mathrm{C}(87 \%)$ and $25{ }^{\circ} \mathrm{C}(74 \%)$ (room temperature; $\mathrm{RT}$ ) indicate that phage incorporated products can easily be stored at RT at least for a short period of time $(1 \mathrm{~h})$. AHP-1 was inactive in highly acidic conditions $(<\mathrm{pH} 4)$ and highly alkaline conditions ( $>\mathrm{pH}$ 10) (Fig. 1e). A previously characterized A. hydrophila phage, pAh-1 [19] showed similar stability in these temperatures and $\mathrm{pH}$ conditions, and it was stable in more acidic $\mathrm{pH}(\mathrm{pH} 3)$ than AHP-1. Studied salinities $(0.1-3.5 \%)$ were found to preserve AHP-1 phage infectivity
1 in a range of temperatures $\left(4-65^{\circ} \mathrm{C}\right), \mathrm{pH}(2-14)$, salinity $(0.1-3.5 \%)$, and different organic solvents (chloroform, ethanol; $\mathrm{EtOH}$, diethyl ether, acetone). Phage stability percentages of temperature, $\mathrm{pH}$, salinity, and organic solvents were calculated based on $4{ }^{\circ} \mathrm{C}, 10,2 \%$, and SM buffer, respectively. Error bars represent mean $\pm \mathrm{SE}$

regardless of their concentrations. Furthermore, AHP-1 showed almost similar high stability (100\%) in chloroform and SM buffer, while, its infectivity totally lost after incubation in ethanol, acetone, and diethyl ether (Fig. 1e).

\section{Bacterial growth inhibition of AHP-1}

A. hydrophila growth inhibition was assessed using the treatment of AHP-1 and chloramphenicol separately, and with combination of those two (Fig. 2a-c). Phage treatment showed MOI-dependent bacteria growth inhibition, and highest growth inhibition was acquired at 10 MOI. Considering chloramphenicol treatments, growth 
inhibition was lower for both 10 and $25 \mu \mathrm{g} \mathrm{mL}{ }^{-1}$ compared to low concentrations (2.5 and $\left.5 \mu \mathrm{g} \mathrm{mL}{ }^{-1}\right)$ and non-treated control, but still showing an increasing trend. At 2.5 and $5 \mu \mathrm{g} \mathrm{mL} \mathrm{m}^{-1}$, A. hydrophila cultures showed similar growth rates $\left(\mathrm{OD}_{595}=0.553\right.$ and 0.515 at $20 \mathrm{~h}$, respectively and 0.796 and 0.690 at 24 $\mathrm{h}$, respectively), but it was slightly lower compared to control $\left(\mathrm{OD}_{595}=0.721\right.$ and 0.999 at 20 and $24 \mathrm{~h}$, respectively). Thus we selected $5 \mu \mathrm{g} \mathrm{mL} \mathrm{m}^{-1}$ for further studies of testing the combined effect of the AHP-1 and chloramphenicol treatment. Interestingly, combined treatment was more effective in killing A. hydrophila showing the highest growth inhibition at chloramphenicol
(5 $\mu \mathrm{g} \mathrm{mL}^{-1}$ ) plus AHP-1 (10 MOI). However, bacteria started to grow after about $15 \mathrm{~h}$ of treatment, which might be due to the presence of resistant bacteria, thus further elucidations are necessary to address the issue. Moreover, the indicator host, MDR A. hydrophila found to be intermediately resistant to chloramphenicol, suggesting that controlling A. hydrophila infection is difficult with chloramphenicol. Chloramphenicol is a broad spectrum anti-microbial agent which effectively controls many Gram-negative and positive bacteria. Nevertherless, low concentration doses are often recomended for administration, since high doses can often lead to adverse effects in both animals and
Fig. 2 Comparison of individual and combined in vitro effect on A. hydrophila growth inhibition over the time with AHP-1 and chloramphenicol: a growth inhibition by AHP-1 at different MOI $(10,1,0.1$, and 0.01$)$, b growth inhibition by chloramphenicol at different doses $(2.5,5,15$, and $\left.25 \mu \mathrm{g} \mathrm{mL}^{-1}\right)$, c combined effect on growth inhibition by AHP-1 and chloramphenicol. Error bars represent mean $\pm \mathrm{SE}$; chloramphenicol $=$ Chlorm
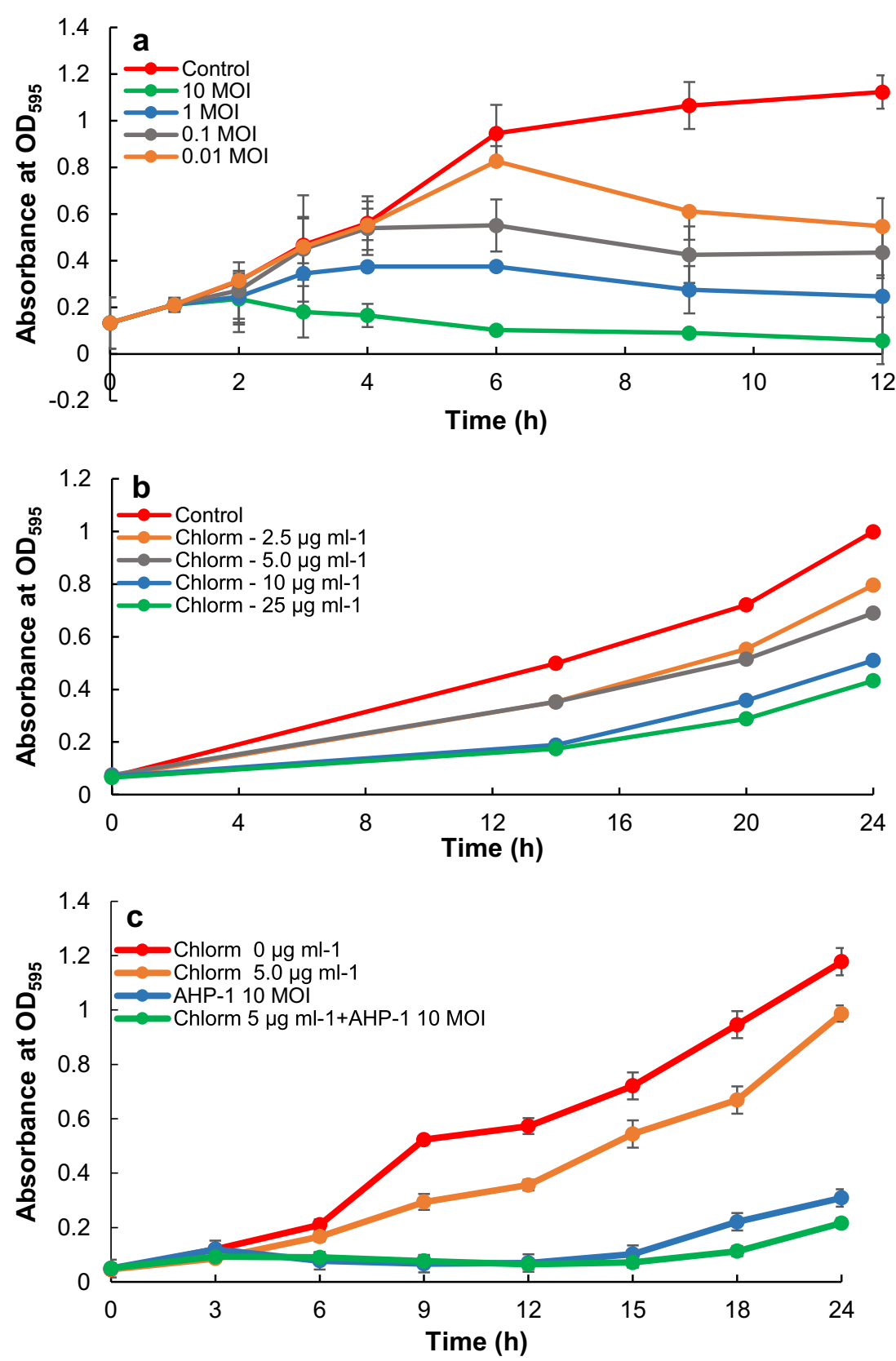
humans. Therefore, in many countries, cloramphenicol is banned to be used for food animals [23]. In consistence with our results, combination of antibiotics and phagedemonstrated synergistic effects in killing Pseudomonas aeruginosa biofilms, and with phage, lower concentrations of antibiotics could be used more effectively [24]. Therefore, our results suggest that phage treatment is highly effective in controlling bacterial growth inhibition, and under certain circumstances, low concentrations of antibiotics can be used to enhance the effect. However, as these arguments are solely based on in vitro experiments, in vivo experiments are needed to perform to get better view of the combine effect of AHP-1 and antibiotic therapy on bacterial growth inhibition.

\section{Phage safety analysis by immune responses of zebrafish to AHP-1}

One of the main concerns that hinders the development of effective phage therapy is immunogenicity of phage particles. Safety of using AHP-1 as a potential therapeutic was examined by exposing zebrafish to AHP-1 continuously for 12 days. Reactive oxygen species, sod-1, and out of inflammatory cytokines only ill-6 showed significant $(P<.05)$ elevated relative mRNA expression levels at day 4 , yet at day 12 , it reduced to non-significant levels $(P>.05)$ compared to control. Transcriptional responses of inflammatory mediators, $\operatorname{tnf}-\alpha$, $i l 1-\beta, i l-10$ and chemokine, and $c x c l-8 a$ showed slight nonsignificant induction $(P>.05)$ compared to control during

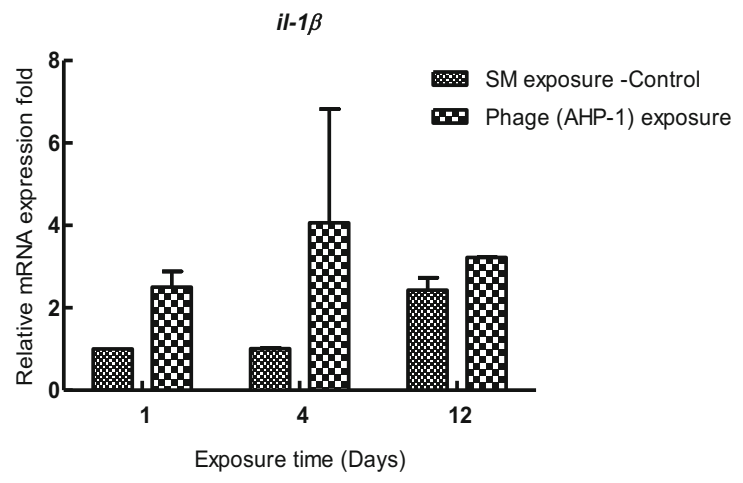

il-6
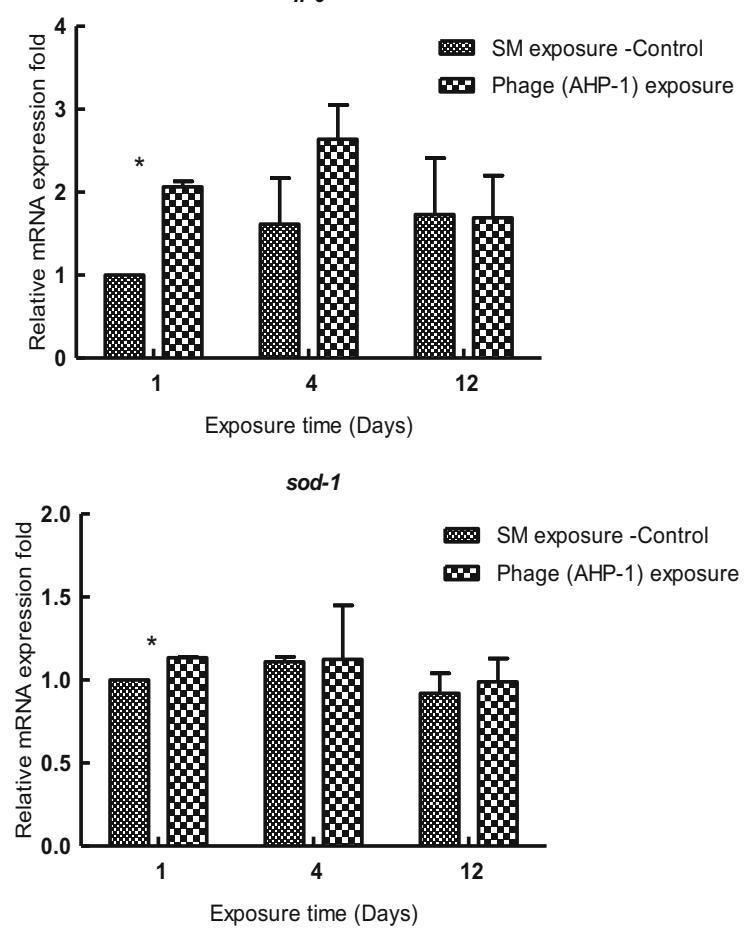

$=3$ ) at each time point for each replicate group. Relative mRNA expression fold change for a particular candidate gene of SM buffer exposed fish at day $1=1$. Asterisk represents significantly different $(P<.05)$ values with controls. Error bars represent mean $\pm \mathrm{SE}$ 
the continuous exposure to AHP-1 (Fig. 3). Previous studies speculated that structural proteins present on phage surfaces can be recognized as foreign antigens by host immune system, thus stimulate immune responses. Moreover, it has been reported that, due to bacterial endotoxins like LPS, remains of bacteria lysis, which may present in phage preparations or produce by sudden lysis of many bacteria cells, can induce acute immune responses [25]. Phage-induced immune responses could be beneficial in treatment processes such as cancer immunotherapy, where bacteriophage induced local immune responses can help to eliminate tumors [26]. A recent study suggested that $A$. hydrophila phage lysate, which induced robust immune responses in Cyprinus carpio, could be used as novel-inactivated antigen in fish vaccine development [27]. Moreover, TNF- $\alpha$ level in serum and the production of TNF- $\alpha$ and IL- 6 by blood cell cultures can be normalized by the effective phage therapy [28].

However, continuous exposure to the same phage may activate adaptive immune responses followed by antibody production, which elicits a negative impact on its effective treatment [29]. In this study, low levels of immune responses in zebrafish by AHP-1 ensured safety, with respect to phage adaptation in phage therapy.But the different modes of phage administration, bacterial infection, and their interactions need to be deeply examined, because phage propagation is greatly enhanced at the infection site, and high inflammatory responses could be disadvantageous.

In conclusion, newly isolated and characterized AHP-1 could inhibit growth of $A$. hydrophila more effectively than chloramphenicol, suggesting that AHP-1 has potential to be an important tool for controlling bacteria colonization. Also, combination of low dose of antibiotics and the phages may be highly effective. However, the combined use of AHP-1 with a low dose of antibiotics for controlling bacteria colonization should be approached with caution, because with low antibiotic concentrations, other groups of bacteria on which the AHP-1 do not have any effect could be grown. Thus, developing a cocktail combining multiple phages with low dose of antibiotics might have greater chance of high efficacy to control the target host, which needs to be researched in future studies. No detrimental immune responses in zebrafish upon postAHP-1 exposure ensured the safety on mode of phage administration, and could aim the studies for developing promising phage therapy or phage-based vaccine strategy. However, detailed genetic characterizations are needed to detect any unfavorable genes (toxin, virulence, and lysogeny-associated genes), before selecting AHP-1 as an alternative antibiotic.

Funding information This work was supported by the National Research Foundation of Korea (NRF) grant funded by the government of Korea (MSIT) (2017010990).
Compliance with ethical standards Zebrafish experiments were conducted in accordance with the institutional animal care guidelines and supervision of committees of Chungnam National University (CNU-00866).

Conflict of interest The authors declare that they have no conflict of interest.

\section{References}

1. Zaman SB, Hussain MA, Nye R, Mehta V, Mamun KT, Hossain N (2017) A review on antibiotic resistance: alarm bells are ringing. Cureus 9:e1403. https://doi.org/10.7759/cureus.1403

2. Aslam B, Wang W, Arshad MI, Khurshid M, Muzammil S, Rasool MH, Nisar MA, Alvi RF, Aslam MA, Qamar MU, Salamat MKF, Baloch Z (2018) Antibiotic resistance: a rundown of a global crisis. Infect Drug Resist 11:1645-1658. https://doi.org/10.2147/IDR. S173867

3. Miranda CD, Godoy FA, Lee MR (2018) Current status of the use of antibiotics and the antimicrobial resistance in the Chilean salmon farms. Front Microbiol 9:1-14. https://doi.org/10.3389/fmicb.2018. 01284

4. Salmond GPC, Fineran PC (2015) A century of the phage: past, present and future. Nat Rev Microbiol 13:777-786. https://doi.org/ $10.1038 /$ nrmicro3564

5. Rose T, Verbeken G, De Vos D, Merabishvili M, Vaneechoutte M, Lavigne R, Jennes S, Zizi M et al (2014) Experimental phage therapy of burn wound infection: difficult first steps. Int J Burns Trauma 4:66-73

6. King A, Lefkowitz E, Adams M, Carstens E (2012) Virus taxonomy, 1st edn. Elsevier, Amsterdam, pp 39-45

7. Le TS, Nguyen TH, Vo HP, Doan VC, Nguyen HL, Tran MT, Tran TT, Southgate PC, Kurtboke DI (2018) Protective effects of bacteriophages against Aeromonas hydrophila causing motile Aeromonas septicemia (MAS) in striped catfish. Antibiotics 7(1): 16. https://doi.org/10.3390/antibiotics7010016

8. Citterio B, Biavasco F (2015) Aeromonas hydrophila virulence. Virulence 6:417-418. https://doi.org/10.1080/21505594.2015. 1058479

9. Igbinosa IH, Igumbor EU, Aghdasi F, Tom M, Okoh AI (2012) Emerging Aeromonas species infections and their significance in public health. Sci World J 2012:625023. https://doi.org/10.1100/ 2012/625023

10. Chandrarathna HPSU, Nikapitiya C, Dananjaya SHS, Wijerathne CUB, Wimalasena SHMP, Kwun HJ, Heo GJ, Lee J, De Zoysa M (2018) Outcome of co-infection with opportunistic and multidrug resistant Aeromonas hydrophila and A. veronii in zebrafish: identification, characterization, pathogenicity and immune responses. Fish Shellfish Immunol 80:573-581. https://doi.org/10.1016/j.fsi. 2018.06.049

11. Pu W, Guo G, Yang N, Li Q, Yin F, Wang P, Zheng J (2019) Three species of Aeromonas (A. dhakensis, A. hydrophila, and A. jandaei) isolated from freshwater crocodiles (Crocodylus siamensis) with pneumonia and septicemia. Lett Appl Microbiol 68:212-218. https://doi.org/10.1111/lam.13112

12. Nikapitiya C, Dananjaya SHS, Chandrarathna HPSU, Senevirathne A, De Zoysa M, Lee J (2019) Isolation and characterization of multidrug resistance Aeromonas salmonicida subsp. salmonicida and its infecting novel Phage ASP-1 from Goldfish (Carassius auratus). Indian J Microbiol 59:161-170. https://doi.org/10.1007/ s12088-019-00782-5

13. Pridgeon JW, Klesius PH, Lewbart GA, Daniels HV, Jacob M (2014) Edwardsiella tarda and Aeromonas hydrophila isolated 
from diseased Southern flounder (Paralichthys lethostigma) are virulent to channel catfish and Nile tilapia. J Coast Life Med 2: 337-343. https://doi.org/10.12980/JCLM.2.2014JCLM-20140005

14. Aboyadak IM, Ali NGM, Goda AMAS, Aboelgalagel WH, Salam AME (2016) Molecular detection of Aeromonas hydrophila as the main cause of outbreak in Tilapia farms in Egypt. J Aquac Mar Biol 2:00045. https://doi.org/10.15406/jamb.2015.02.00045

15. Yang Y, Miao P, Li H, Tan S, Yu H, Yu H (2017) Antibiotic susceptibility and molecular characterization of Aeromonas hydrophila from grass carp. J Food Saf 38:e12393. https://doi.org/10.1111/jfs. 12393

16. Anand T, Vaid RK, Bera BC, Singh J, Barua S, Virmani N, Rajukumar K, Yadav NK, Nagar D, Singh RK, Tripathi BN (2016) Isolation of a lytic bacteriophage against virulent Aeromonas hydrophila from an organized equine farm. J Basic Microbiol 56:432-437. https://doi.org/10.1002/jobm.201500318

17. Vincent AT, Paquet VE, Bernatchez A, Tremblay DM, Moineau S, Charette SJ (2017) Characterization and diversity of phages infecting Aeromonas salmonicida subsp. salmonicida. Sci Rep 7:1-10. https://doi.org/10.1038/s41598-017-07401-7

18. El-Araby DA, Gamal ED, Megahed THM (2016) New approach to use phage therapy against Aeromonas hydrophila induced motile Aeromonas septicemia in Nile Tilapia. J Mar Sci Res Dev 6:6-11. https://doi.org/10.4172/2155-9910.1000194

19. Easwaran M, Dananjaya SHS, Park SC, De Zoysa M, Shin HJ (2016) Characterization of bacteriophage pAh-1 and its protective effects on experimental infection of Aeromonas hydrophila in Zebrafish (Danio rerio). J Fish Dis 40:841-846. https://doi.org/ $10.1111 / \mathrm{jfd} .12536$

20. Lindberg HM, McKean KA, Wang IN (2014) Phage fitness may help predict phage therapy efficacy. Bacteriophage 4:e964081. https://doi.org/10.4161/21597073.2014.964081

21. Rakhuba DV, Kolomiets EI, Szwajcer Dey E, Novik GI (2010) Bacteriophage receptors, mechanisms of phage adsorption and penetration into host cell. Pol J Microbiol 59:145-155. https://doi. org/10.1016/j.micres.2015.01.008.1.94

22. Gatedee J, Muangman S, Pumirat P, Mahakunkijcharoen Y, Prasertsincharoen N, Kritsiriwuthinan K (2017) Isolation and biological characterization of bacteriophages which infect Aeromonas hydrophila. J Appl Anim Sci 10:9-18

23. Papich MG (2016). Saunders handbook of veterinary drugs. 4th edn. Saunders, pp.148-150.

24. Chaudhry WN, Concepcion-Acevedo J, Park T, Andleeb S, Bull JJ, Levin BR (2017) Synergy and order effects of antibiotics and phages in killing Pseudomonas aeruginosa biofilms. PLoS ONE 12:1-16. https://doi.org/10.1371/journal.pone.0168615

25. Krut O, Bekeredjian-Ding I (2018) Contribution of the immune response to phage therapy. J Immunol 200:3037-3044. https://doi. org/10.4049/jimmunol.1701745

26. Eriksson F, Tsagozis P, Lundberg K, Parsa R, Mangsbo SM, Persson MAA, Harris RA, Pisa P (2009) Tumor-specific bacteriophages induce tumor destruction through activation of tumorassociated macrophages. J Immunol 182:3105-3111. https://doi. org/10.4049/jimmunol.0800224

27. Yun S, Jun JW, Giri SS, Kim HJ, Chi C, Kim SG, Kim SW, Kang JW, Han SJ, Kwon J, Oh WT, Park SC (2019) Immunostimulation of Cyprinus carpio using phage lysate of Aeromonas hydrophila. Fish Shellfish Immunol 86:680-687. https://doi.org/10.1016/j.fsi. 2018.11.076

28. Weber-Dąbrowska B, Zimecki M, Mulczyk M (2000) Effective phage therapy is associated with normalization of cytokine production by blood cell cultures. Arch Immunol Ther Exp 48:31-37

29. Henein A (2013) What are the limitations on the wider therapeutic use of phage? Bacteriophage 3. https://doi.org/10.4161/bact.24872

Publisher's note Springer Nature remains neutral with regard to jurisdictional claims in published maps and institutional affiliations. 